MATEC Web of Conferences 19, 01002 (2014)

DOI: $10.1051 /$ matecconf/ 20141901002

CC Owned by the authors, published by EDP Sciences, 2014

\title{
The reliability of the power semiconductor module on the operating temperature
}

\author{
Evgeny V. Kravchenkoa, Dariya Yu. Ivleva \\ National Research Tomsk Polytechnic University, 634050 Tomsk, Russia
}

\begin{abstract}
A comparison of the intensities of the failure of a power unit with the real thermal regime of the device under conditions of natural convection and obtained by using statistical data analysis. The integrated assessment of reliability based on the methods of physics failures. The necessity of taking into account the actual non-stationary temperature fields to improve the reliability of the forecast operating life of power semiconductor devices.
\end{abstract}

\section{Introduction}

Modern methods of analysis of thermal power electronics device modes based on various software packages (e.g., Flow Vision [1]). Known and different approaches, based on mathematical modeling: simplified mathematical models [2,3]; method of heating circuits (thermal resistance) [4,5]; quantitative thermography and thermal monitoring [6]; finite element [5]; finite-difference methods [7], taking into account natural convection [8] in conjunction with heat radiation [9] on the stationary [10] and cyclic modes [11].

In fact, predicting the reliability of any power system, as a rule, is carried out on the basis of apriority information [12,13]. Common to all methods of predicting reliability indices of energy facilities is the analysis of statistical data [14-17]. But these methods have significant limitations. This is due not only to the possible lack of information on conditions, operating conditions, and storage of power devices, but with the rules of sampling devices for testing [18,19]. Also, the lack of highobjects-analogues in the development of, for example, new devices to a particular industry [20]. The assumption of steady-state operation of the devices themselves and the operating conditions are not always justified. For example, changes in temperature of the power semiconductor devices in time can be 30 degrees or more [21] and the temperature field of power devices themselves is essentially nonstationary. It can be concluded that the resource efficiency power electronics devices depend strongly on the thermal conditions of their work.

Another approach for predicting the reliability of the power system, based on the physics of failure (POF - Physics of Failure) analysis [22-29]. The reliability of the power system is viewed from its components, taking into account the aging [22] in conjunction with the effect of adverse weather conditions. [23] Indicators of reliability of the power system are determined by using a mathematical model of degradation of cable products. [24] Assess the residual life of isolation of electrical devices were obtained [25] on the basis of the generalized polarization index and the experimental data on the

\footnotetext{
${ }^{\text {a }}$ Corresponding author: e-mail: kevatp@tpu.ru
} 
change in the intensity of partial discharge in the aging process of the dielectric [26]. Reliability indices of a number of electrical devices are defined taking into account the degradation of the polymer components [27-29]. But the analysis of the physics of failure is usually carried out without taking into account the spatial distribution of temperature change in the time of the objects [22-27].

The aim of this work - the reliability analysis of power semiconductor devices based on the numerical simulation of unsteady non-uniform temperature field in the presence of several local heat sources located in the natural convection at different operating temperatures.

\section{Analysis of the thermal mode of the power semiconductor device}

Modern power devices can be formally divided into two groups. The first group of devices used primarily for converting very large capacities, include diodes and thyristors. The second groups of devices that are used in a range of small and medium capacity represent the field (MOSFET - metaloxide-semiconductor field effect transistor) and bipolar field-effect transistors (IGBT - Insulated-gate bipolar transistor).

Analysis of warm mode was based on typical power electronics relatively simple device - power diode module with a transition temperature see point $\mathrm{T}_{\text {iunct }}=125^{\circ} \mathrm{C}$. (Fig.1).

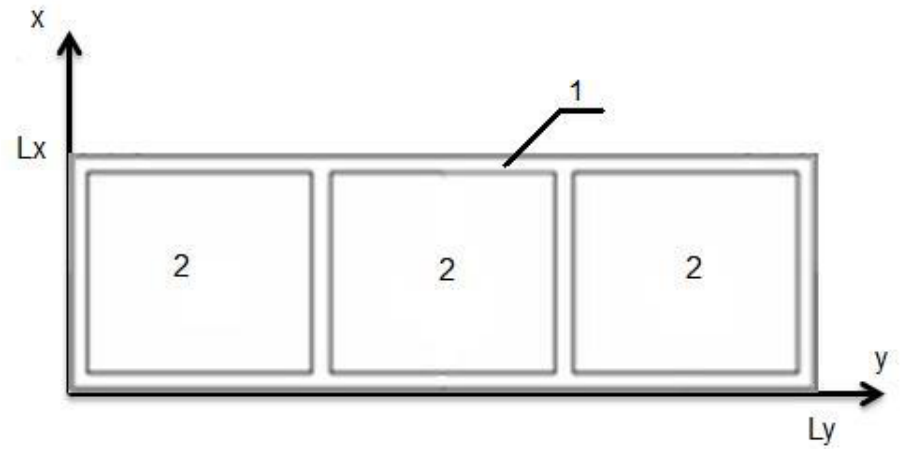

Figure 1. The geometry of solutions (1,2 - area with different thermal characteristics).

It was assumed that the model (plate) includes areas with different thermal characteristics. In three areas (area 2, Figure 1.) Is a local heat given intensity Q. At the edges of the plate boundary conditions of the kind III (mixed heat transfer).

Key assumptions used in the formulation of the problem.

1 Thermal characteristics of the materials does not depend on temperature.

2 Thermal contact at the boundaries between the areas $(1,2)$ is considered ideal.

In such context, the task comes to the solution of non-stationary thermal conductivity equation:

$$
C(x, y) \rho(x, y) \frac{\partial T}{\partial t}=\frac{\partial}{\partial x}\left(\lambda(x, y) \frac{\partial T}{\partial x}\right)+\frac{\partial}{\partial y}\left(\lambda(x, y) \frac{\partial T}{\partial y}\right)+\frac{Q(t, x, y)}{S h}+\frac{\alpha(T)\left(T_{\text {ext }}-T\right)}{h}+\frac{\varepsilon_{\text {ref }} \sigma\left(T_{\text {ext }}^{4}-T^{4}\right)}{h}
$$

with the appropriate initial:

$$
\left.t \in\left[0 ; t_{\max }\right] \quad x \in\left[0 ; L_{x}\right] \quad y \in\left[0 ; L_{y}\right] \quad T\right|_{t=0}=T_{0}(x, y, z)
$$

and boundary conditions:

$$
\begin{aligned}
& x=0, y \in\left[0 ; L_{y}\right], z \in\left[0 ; L_{z}\right]: \\
& x=L_{x}, y \in\left[0 ; L_{y}\right], z \in\left[0 ; L_{z}\right]: \\
& y=0, x \in\left[0 ; L_{x}\right], z \in\left[0 ; L_{z}\right]:
\end{aligned}
$$

$$
\begin{aligned}
& -\lambda \frac{\partial T}{\partial x}=\alpha(T)\left(T_{\text {ext }}-T\right)+\varepsilon_{\text {ref }} \sigma\left(T_{\text {ext }}^{4}-T^{4}\right), \\
& \lambda \frac{\partial T}{\partial x}=\alpha(T)\left(T_{\text {ext }}-T\right)+\varepsilon_{\text {ref }} \sigma\left(T_{\text {ext }}^{4}-T^{4}\right), \\
& -\lambda \frac{\partial T}{\partial y}=\alpha(T)\left(T_{\text {ext }}-T\right)+\varepsilon_{\text {ref }} \sigma\left(T_{\text {ext }}^{4}-T^{4}\right),
\end{aligned}
$$




$$
y=L_{y}, x \in\left[0 ; L_{x}\right], z \in\left[0 ; L_{z}\right]: \quad \lambda \frac{\partial T}{\partial y}=\alpha(T)\left(T_{\text {ext }}-T\right)+\varepsilon_{\text {ref }} \sigma\left(T_{\text {ext }}^{4}-T^{4}\right)
$$

Where: $\mathrm{C}$-heat capacity; $\rho$ - density; T-temperature; $\mathrm{t}$ - time; $\lambda$ - thermal conductivity coefficient; $\mathrm{Q}$ - heat source; S-source area; $h$ - plate thickness; $\alpha$ - convective heat transfer coefficient of the surface; $\mathrm{T}_{\text {ext }}$ - environment temperature; $\sigma$ - Stefan-Boltzmann constant; $\varepsilon_{\text {ref }}-$ the emissivity of the surface of the plate and the environment; $\mathrm{x}, \mathrm{y}$ - coordinates.

A method for solving a differential equation similar to that described in the article $[11,30]$.

\section{Analysis of reliability indicators of power semiconductor device}

The analysis of the reliability indices of the diode module two mathematical models such as-Arrhenius [31] and a multiplicative model [19] were selected. The mathematical multiplicative model [19] of the reliability evaluation diode module is shown below

$$
\lambda_{e}=\lambda_{b} \cdot \mathrm{K}_{p} \cdot \mathrm{K}_{f} \cdot \mathrm{K}_{k} \cdot \mathrm{K}_{e},
$$

where: $\lambda_{b}$-base failure rate of the power unit; $K_{p}$ - coefficient of mode, depending on the temperature and the electric load; $\mathrm{Kf}$-functional specificity mode device coefficient; Kk -level of quality coefficient; $\mathrm{Ke}-$ stiffness conditions.

It is important to note that the basic failure rate used in the mathematical models of the type (3) In determining the reliability indices $(\lambda \mathrm{b})$ are given for the temperature of $25^{\circ} \mathrm{C}$ [19] and do not include, for example, the spatial inhomogeneity of temperature fields inside products, and for him outside.

Therefore, the analysis of reliability indices of a typical power electronics device (diode module) is also carried out on the basis of a mathematical model, for which $\mathrm{T}$ is one of the most important factors [31]. In accordance with the Arrhenius model failure rate depends exponentially on the temperature [31]:

$$
\lambda_{\mathrm{A}}(T)=C \cdot \exp \left(\frac{-E}{k T}\right)
$$

Where: C-constant, E-activation energy, k-Boltzmann constant.

The temperature used according to (4), was determined from the results of the two-dimensional non-stationary solutions of the heat equation (2) with the appropriate boundary conditions.

\section{Results and discussion.}

The characteristic form of the temperature field simulation object (diode module) at ambient temperature $\mathrm{T}=25^{\circ} \mathrm{C}$ at time $\mathrm{t}=900 \mathrm{c}$ is shown in Figure 2.

Shown in Fig. 2 the temperature field of power semiconductor device is typical for the given initial conditions and the operation mode. Analysis heat flow through the surface of the module (Fig. 1) shows that the temperature of the heated region (Fig. 2) at 5-10 K higher than see point $\mathrm{T}_{\text {junct. }}$. Temperature field of the device under consideration is essentially non-uniform and is characterized by significant gradients of $\mathrm{T}$.

As an example, considered two on-off cycles at various intervals (Fig. 3). Analysis of resource power device using the Arrhenius model is advisable for the average $\left(\mathrm{T}_{\mathrm{av}}\right)$ and maximum $\left(\mathrm{T}_{\max }\right)$ temperatures of the object.

Increase in ambient temperature leads to a $\mathrm{T}$ for adequate growth model for the two options. Thus, temperature control operation of the power module of approximately $10 \mathrm{~K}$ below the second embodiment. 


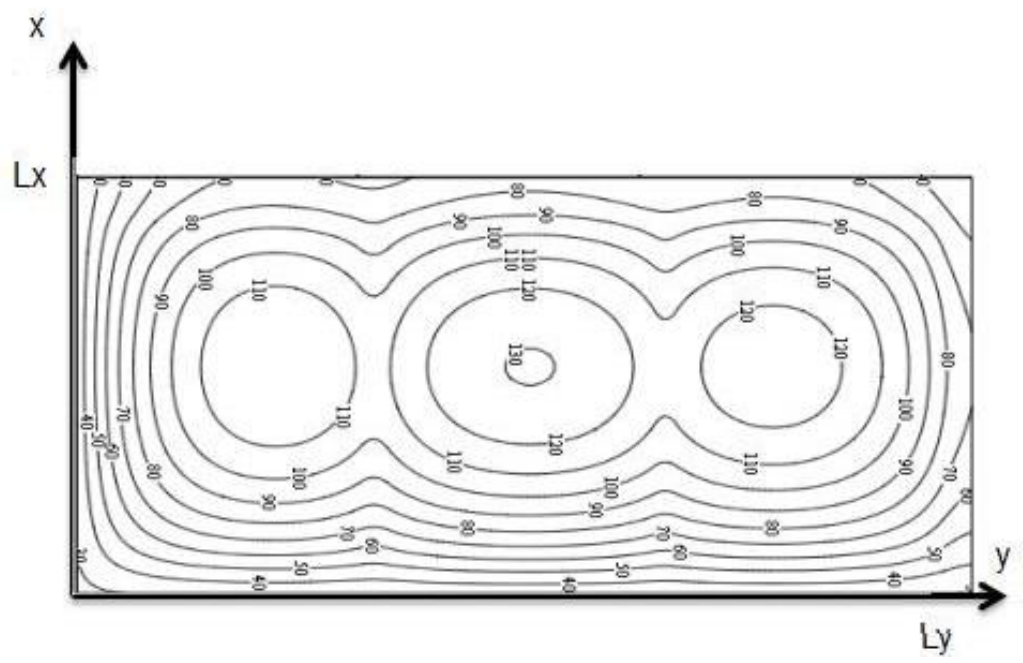

Figure 2. Temperature field of the simulated object (the temperature in degrees Celsius).

The results of numerical modeling of indicators of reliability (failure rate) power semiconductors are shown in Fig. 4. The behavior of the failure rate $\lambda_{A}(T)$ reflects not only the significant differences in the estimates of reliability models (3) and (4), but also a high degree of dependence of the Arrhenius model prediction (curves 1 and 2 in Fig. 4) of the estimated (accepted) temperature.

Dependency analysis presented in Figure 4 indicates that the numerical value calculated by the Arrhenius model (4), a 5-fold higher in Tmax relative to the time $\mathrm{T}_{\mathrm{av}}$ of $1000 \mathrm{~s}$. and an ambient temperature of $300 \mathrm{~K}$ (see Fig. 4a). The failure rate of the power semiconductor device, as determined by the model (4), for the Tav (curve 2 in Fig. 3), 29 times more than for the multiplicative model (3) at $\mathrm{t}=1000 \mathrm{~s}$. Reducing the time of switching cycles (example №2 on Fig.3b) increases the operational reliability (life) is almost a factor of 2 hands (Fig. 4b).

With increasing ambient temperature increases the failure rate of the power semiconductor device. Dependency analysis on Figure 4c and 4d shows that variants №1 reliability index below about twice and a little more than twice for the variant №2 at maximum failure rates.

According to [23], in semiconductor devices are not microwave at $80 \%$ of cases occur parametric failures. This type of failure is associated with physical and chemical processes of degradation (aging) of the semiconductor device structure. As is well known, the aging rate (accumulation of degradation state) depends not only on the initial state of the power semiconductor device, but the electrical load modes and operating conditions of temperature and storage [22,23,37]. Figure 4 shows an integral characteristic of the failure rate, which is the rate of consumption of electrical power resource devices.

Dependency Analysis (Fig.4a and Fig.4b) shows that the resource is a power device in the 1.6 and 1.8 times higher for the variant №2 at Toff and Tmax, respectively. With increasing temperature, the environment an integral indicator of reliability for the variant №1 (Fig. 4c) above 1.5 and 1.7 times compared to the example №2 (Fig. 4d). 
The $2^{\text {nd }}$ International Youth Forum "Smart Grids"
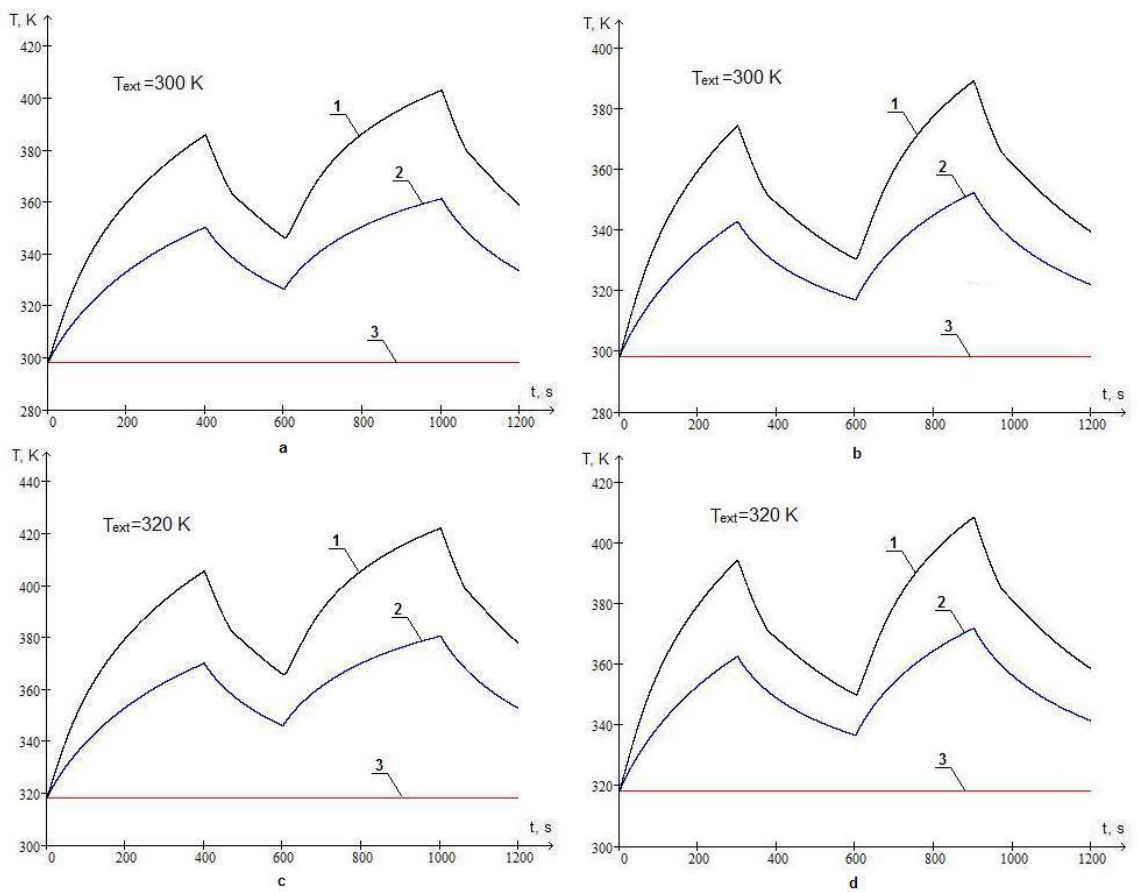

Figure 3. The dependence of temperature versus time for various cycles of ON-OFF. ( 1 - the maximum temperature model $\left(\mathrm{T}_{\max }\right)$, and 2 - the average temperature of the model $\left(\mathrm{T}_{\mathrm{av}}\right), 3$ - constant temperature $\left(\mathrm{T}_{\text {const }}\right)$.
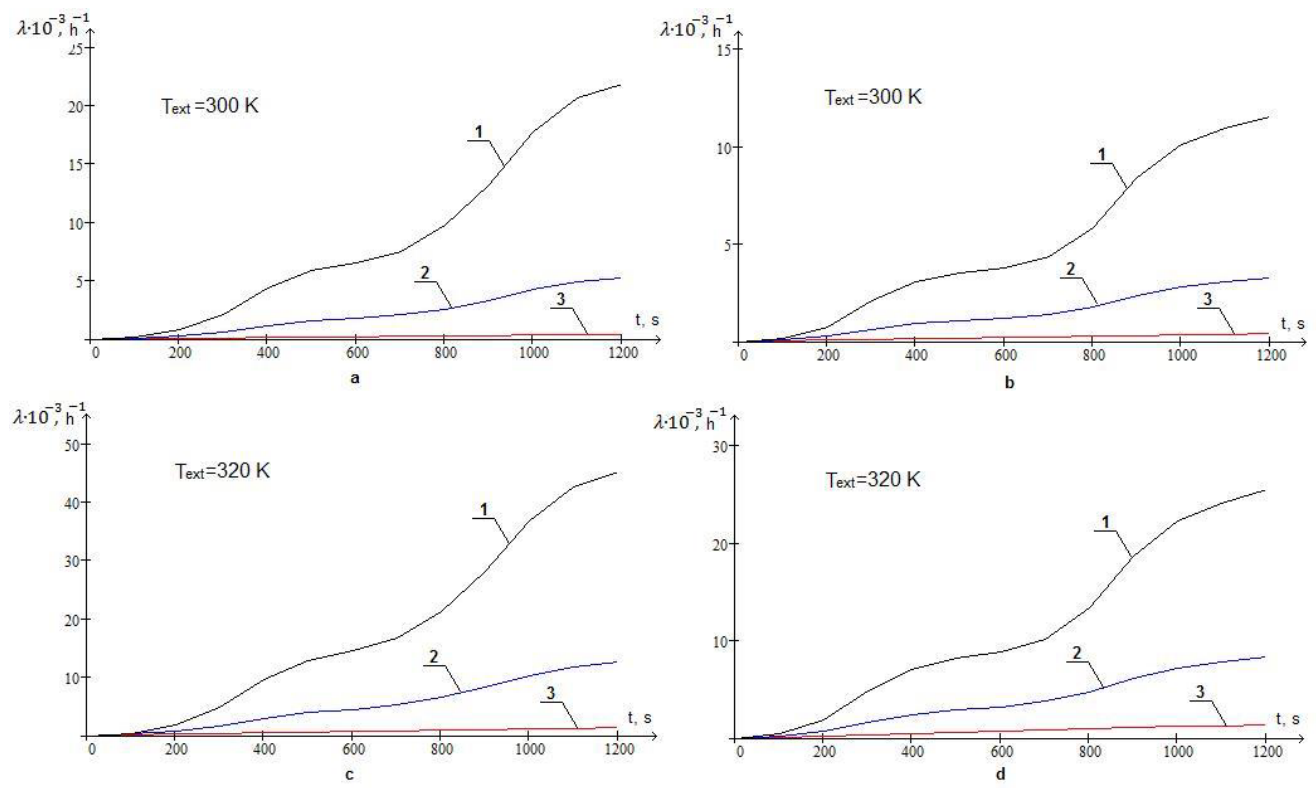

Figure 4. Integral characterization of failure rate versus time for various cycles of ON-OFF. (1 - Arrhenius model $\left(\mathrm{T}_{\max }\right), 2$ - Arrhenius model $\left(\mathrm{T}_{\mathrm{av}}\right), 3$ - multiplicative model $\left(\mathrm{T}_{\text {const }}\right)$. 


\section{Conclusions}

Reliability of power semiconductor devices should be carried out on the basis of analysis of the real non-stationary inhomogeneous thermal mode of the device.

The proposed mathematical apparatus allows you to manage the resource of power semiconductor devices. Also, on the basis of the new approach may predict the reliability of power devices in applications such as locomotives, elevator, tram and subway, for which there is no statistical information. That will increase energy efficiency in their respective fields.

The reported study was supported by the Grant of the RFFI (project № 14-08-00057).

\section{References}

1. A.A. Aksenov, S.V. Zhluktov, Bulletin of the Russian Academy of Sciences, 2, (2013)

2. V. Ya. Bespalov, Yu. A. Moshinskiy, Electrical Technology Russia, 4, (2003)

3. P.van Duijsen, P. Bauer, J. Leuchter, EPE/PEMC, 1, (2010)

4. A. V. Bulichev, E. Yu. Erochin, Russian Electrical Engineering, 3, (2011)

5. E.C.W Jong, J.A. Ferreira, P. Bauer, Pow.Elect.Let., IEEE, 3, (2005)

6. A.B. Vlasov, Electrical, 3, (2012)

7. G.V. Kuznetsov, M.A. Sheremet, Russian Microelectronics, 5, (2009)

8. G.V. Kuznetsov, M.A. Sheremet, Russian Microelectronics, 6, (2010)

9. G.V. Kuznetsov, M.A. Sheremet, Russian Microelectronics, 5, (2011)

10. E.V. Kravchenko, D.JU Ivleva, Fundamental research, 6-5, (2013)

11. G.V. Kuznetsov, E.V. Kravchenko, Elektromagnitnye Volny i Elektronnye Systemy, 10 (1112), (2005)

12. Yu. A. Fokin, Ya. N. Osipov, Electrical Technology Russia, 5, (2010)

13. V.V. Afanasev, V.M. Kozhevnikov, Reability, 3, (2012)

14. V.V. Izmailov, M.V Novoselova, Russian Electrical Engineering, 5, (2009)

15. M.A. Novikov, P.A. Rashitov, Russian Electrical Engineering, 12, (2013)

16. V.M. Saltykov, L.M. Suleimanova, Electromechanics, 6, (2007)

17. M.Sefidgaran, M. Mirzaie, A. Ebrahimzadeh, Int.J. of Elect.Pow.\&Ener.Sys, 35, (2012)

18. G.M. Sevenov, A.V. Suchov, Russian Electrical Engineering, 10, (2006)

19. S.F. Prytkov, V.M. Gorbachev, Handbook «Reliability of radioelements» (Moscow, 2012)

20. F. Demut, A. Kolpakov, Power electronics, 27, (2010)

21. G.V. Kuznetsov, A.V. Belozertsev, Radiotechnics, 3, (2006)

22. W. Li, IEEE Trans Power Syst, 17, (2002)

23. M.H.J. Bollen, IEEE Trans Ind Appl, 37, (2001)

24. M. Stötzel, M. Zdrallek, W.H. Wellssow, IEEE Proc Gen Transm Distrib., 48, (2001)

25. F.R. Ismagilov, D.V. Maksudov, Electrical Technology Russia, 2, (2012)

26. E.V. Zenova, V.A. Chernyshov, Bulletin of the MEI, 2, (2011)

27. D.A. Silva, E.C.M. Costa, J.L. Franco, M. Antonionni, R.C. Jesus, S.R. Abreu, K. Lahti, L.H.I. Mei, J. Pissolato, Int.J. of Elect.Pow.\&Ener.Sys., 53, (2013)

28. G.V. Kuznetsov, E.V. Kravchenko, Elektromagnitnye Volny i Elektronnye Systemy, 3, (2014)

29. G.V. Kuznetsov, E.V. Kravchenko, Journal of Engineering Physics and Thermophysics, 80 (5), (2007)

30. E.V. Kravchenko, G.V. Kuznetsov, EPJ Web of Conferences, 76, (2014)

31. A.A. Borisov, V.M. Gorbachev, G.D. Kartashow, M.N. Martynov, S.F. Prytkov, Foreign electronics, 5, (2000) 